\title{
Key Trends and Significant Challenges of Reform and Development of K-12 Education in the New Technological Environment
}

\author{
Hongjun Zhang ${ }^{1, a}$, Zhigang $\mathrm{Wu}^{2}$ \\ ${ }^{1}$ Department of Educational Technology, College of Humanities, Donghua University, Shanghai, China \\ ${ }^{2}$ College of Humanities, Donghua University, Shanghai, China
}

\begin{abstract}
The New Media Consortium (NMC), focusing on tracking the application and development trend of information technology in education and teaching worldwide, released its latest Horizon Report on K-12 education in February 2017. It elaborates on six key trends, six significant challenges and six important technological development in the next five years on a world-wide scale. Therefore, it is necessary to enhance the strategic planning and analysis ability, the quality of teachers' education and digital literacy, and accelerate the application and practice of new technologies such as robotics and makerspaces in K-12 education in order to ensure the healthy and orderly development of China's K-12 education reform.
\end{abstract}

\section{Overview of Horizon Report}

With the rapid development of information technology, Internet technology and the rapid rise of virtual reality, artificial intelligence and other technologies, our learning, work and life in all aspects have changed a lot. They also gradually applied to the field of K-12 education, and have a significant impact. What will be the basic situations of global education in the next five years? What trends and technologies will drive the transformation of K-12 education and teaching? Are there any challenges that can be solved or are insurmountable? How should we formulate effective strategic planning? How will educators cope with these difficulties and challenges effectively? The Horizon Report: 2017 K-12 Edition (hereinafter referred to as the Horizon Report) analyses and answers the above hot issues. ${ }^{[1]}{ }^{[2]}$ The report is a qualitative research project developed by an international non-profit organization, the NMC: New Media Consortium, which tracks the application and development of information technology in education and teaching worldwide. The project includes nearly 300 of the world's most recognized universities, museums, and colleges. Educational and learning institutions such as learning centres and foundations carry out qualitative research and assessment on the application trend of new technologies through the use of Delphi and other research methods with the development and utilization of new media and technologies as the core, and introduce the research results of the project in the form of annual reports. Since 2009, the Horizon Report has published nine consecutive editions. It is the longest global report on the development trend and application of new technologies in the field of K-12 education. ${ }^{[2]}$ The 2017 edition of the Horizon Report was co-authored by MindSpark Learning, the New Media Consortium (NMC) and the School Network Federation (CoSN) and was published on the official website of the New Media Consortium in February 2017. Through understanding and analysis of the horizon Report, we can grasp the latest development status and prospects of the application of new technologies in the field of K-12 education in the world, can judge and predict various trends and challenges, and can provide useful references for understanding the reform and development trend of K-12 education in China in the information age and promote the foundation of our country. Education can better cope with the opportunities and challenges brought by new technologies. ${ }^{[3]}$

The Horizon Report is divided into six key trends, six significant challenges and six important technical development issues. It focuses on policy adjustment, leadership and innovation practices in each issue from the short-term, medium-term and long-term perspectives. Based on an objective and systematic analysis of the core contents and typical cases of the Horizon Report 2017 (K-12 Edition), the author discusses how to face and effectively apply new technologies in the reform and development of K-12 education institutions in China, with a view to paying close attention to K-12 education in China. It provides reference for leaders, managers and front-line teachers of institutional reform and development.

\section{Brief introduction of core content of Horizontal Report}

a Hongjun Zhang:zhjun77@126.com 
The core content of the Horizon Report is to analyse and predict the application of new technologies in K-12 education in the next five years (2017-2021) from a global perspective, and to look at the short-, medium- and long-term trends in the adoption of new technologies in $\mathrm{K}-12$ education, the challenges that can be solved, the difficult challenges and the severe challenges in the application of new technologies, and the areas of K-12 education. Important technologies to be adopted in the current and next five years are discussed in depth, and the content framework is shown in Figure 1.

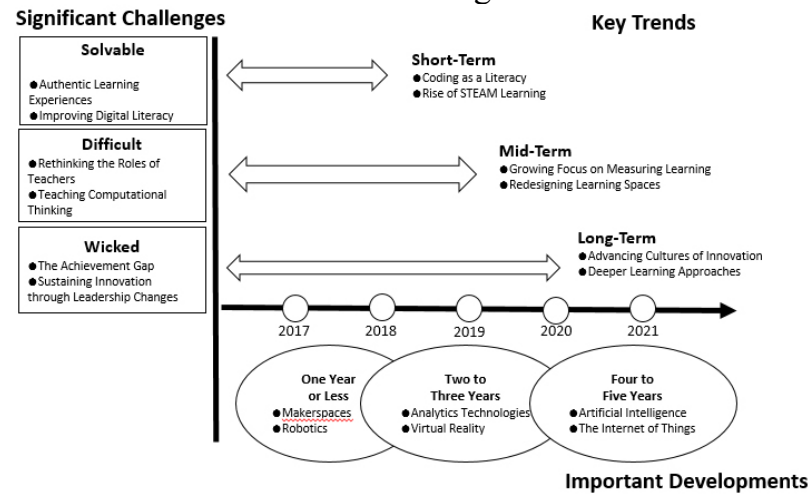

Figure 1. Content framework of the 2017 edition of the New Media Alliance horizontal report (K-12 education Edition).

\section{Rethinking based on the Horizon Report}

The main content of the Horizon Report is the impact of the development and application of new technologies on the reform and development of K-12 education. Reexamination of the contents, cases and innovative significance is not only the proper meaning of interpreting the Horizon Report, but also an effective way for the future K-12 education to actively respond to the challenges of technological innovation and achieve breakthroughs in transformation. It is also an effective way to crack the lack of strategic planning and analytical ability of the leadership team in K-12 education, rigid teacher training mechanism, and lack of training content. After that, the teachers' digital literacy is weak, the understanding of the application of new technology and cognitive deficiencies, and other issues, have a strong reference.

\subsection{Enhancing the strategic planning and analytical ability of the leadership team of K-12 education}

\subsubsection{Enhancing the professionalism of strategic planning}

From a structural point of view, the Horizon Report is divided into three levels: policy adjustment, leadership and innovation practice, which correspond to the system, management and practice of K-12 education. From the content point of view, the Horizon Report divides trends, challenges and new technology applications into three stages: short-term, medium-term and long-term. On the contrary, our country's K-12 education policy planning lacks professionalism and scientificalness, content is broad, focus is not prominent, and operability is not strong. Scientific and professional strategic planning should include preliminary research, target selection and determination, text consideration and writing, implementation of the plan, summary and evaluation, etc. It should be rich in content and complete in system, especially for the current and long-term practical difficulties and challenges in the field of K-12 education. Road, and then complete the qualitative to quantitative transformation, the realization of quantitative stage and goal decomposition, improve the operability of planning.

\subsubsection{Enhance crisis awareness}

A close reading of the Horizon Report reveals that the full text is always problem-oriented and full of crisis awareness, reflecting the philosophical connotations from affirmation to negation, and then to negation to affirmation. The Horizon Report places "bridging the academic performance gap" and "sustaining innovation in leadership change" in the "severe challenges" section to show that economic development, race, and leadership appointment mechanisms have a significant impact on the reform and development of K-12 education. In China, the imbalance of economic development, racial discrimination and backward leadership appointment system also have a profound impact on people's way of thinking, learning and behaviour, hindering the healthy development of K-12 education than other countries may be more serious. Therefore, K-12 education cannot avoid these problems, but should enhance the sense of crisis, and actively respond to these problems in strategic planning.

\subsubsection{Based on the actual situation, comprehensive consideration}

The possible impact of the application of new teaching technologies in K-12 education proposed in the Horizon Report is the outlook and prospect for the future technical planning of K-12 education worldwide. Therefore, while affirming its strong reference value for China's K-12 education, we should be active and prudent in the light of the actual development of K-12 education in China. Treat, do not copy hard move. Because of the imbalance of regional economic development and the great difference in the level of humanistic literacy, the actual development of K-12 education varies greatly from place to place. Even in the same city, there are also great differences due to the influence of various conditions. Therefore, we should take into account the actual situation of people, finance and materials, as well as the good practical experience of other countries with the same type, scale and level of development in the Horizon Report. We should make full investigation and demonstration. We should formulate a phased development plan according to different places and schools. We should not rush it. Especially for the K-12 education institutions in the central and western regions where the economic 
infrastructure is relatively weak, we should not copy the experience of foreign countries wholly and blindly pursue the application of new technology, but should devote more energy to the construction and improvement of $\mathrm{K}$ 12 education infrastructure.

\subsubsection{Coordinating the relationship between technology application and teaching innovation}

The application of new technology will naturally have an important impact on the teaching content and teaching methods of K-12 education institutions. On the one hand, the progress of technology is the driving force for the improvement of teaching quality, while the teaching methods of K-12 education institutions can achieve a qualitative leap only under the support of technology; on the other hand, Teaching is the K-12 education machine. The essence of construction, any advanced ideas and techniques must be presented to the learners through teaching. The technology which is separated from the teaching content is like a rootless tree, a water without source, and loses its application value. Therefore, facing the technological development situation mentioned in the Horizon Report, K-12 education should straighten out the relationship between technology and teaching and seek a balance between them when formulating or adjusting strategic planning. The application of new technology and the innovation of teaching in basic teaching institutions should be synchronized, and the teaching and application prospect of new technology to K-12 education should be taken as an important evaluation standard.

\subsection{Improving the quality of teacher education and data literacy of K-12 education teachers}

\subsubsection{Promoting the integration of Teachers' Education}

The integration of teacher education is "guided by the concept of lifelong education, following the theory and law of teacher professional development, planning and designing the pre-service training and post-service development of teachers, and establishing a new teacher education system and operation mode which is independent of each other and interlinked with each other at all stages of teacher professional development." ${ }^{[3]}$ The training system of Teacher Education in Britain, France and the United States has gradually changed from twolevel separation (pre-service and post-service) to threering integration (pre-service training, induction counselling, post-service improvement) since the 1980s. [4] This integration of pre-service and post-service education has been promoted by replacing normal education with teacher education since the 1980s. ${ }^{[5][6]}$ Since then, the research and practice of Teacher Education Integration has been one of the hot topics in the field of education. The Horizon Report also mentions that pre-service and post-service training of teachers, especially the latter, have an important impact on teaching performance. As far as our country is concerned, although in the process of promoting the mention of teacher education, there are still some problems: the universality of the policy of free normal students in preservice training stage and the separation of students' employment destiny, the diversity of teachers' sources, the discrepancy between qualifications admittance and the integrated design of teacher education, and the alienation of post-service training from welfare. However, we should continue to promote the integration of teacher education, especially in the on-the-job training. Educators should integrate all kinds of resources under the guidance of the concept of lifelong education to achieve the immediate renewal of educational concepts, the immediate optimization of knowledge structure, and the learning and application of new technologies.

\subsubsection{Increase the intensity of educational technology train}

In the information age, the new learning needs of learners put forward unprecedented high requirements for educators, especially for front-line teachers. It is not only embodied in the breadth and depth of professional knowledge, but also in the understanding and application of new technology. Educators should be able to better complete their jobs and help students grow up and develop healthily. On the one hand, they should fully understand and understand the idea that applying new technology to teaching can improve teaching performance; on the other hand, they should continue to learn the new technology mentioned in the Horizon Report and apply it in teaching. Practice. In our country, although there are pre-service normal colleges and universities or specialties for normal students to open courses related to educational technology for normal students to learn some new educational technology, afterservice similar to the "National Program for Educational Technology Capacity Building of Primary and Secondary School Teachers" ${ }^{[7]}$ project for in-service teachers to learn new educational technology, but from the actual effect, It is still difficult for teachers to satisfy learners' new learning needs. Therefore, learn from the excellent cases and experience mentioned in the Horizon Report, actively carry out the integration of pre-service and postservice training and the exploration and practice of various training models.

\subsubsection{Improving teachers' data literacy}

Data literacy is a comprehensive practical ability that teachers should have in the era of big data, and it is also a higher level requirement for teachers' professional ability. Digitalization is the basis of teachers' ability to analyse and process relevant data. Especially in the current big data environment, the lack of data literacy ability of K-12 education workers will hinder the further development of $\mathrm{K}-12$ education. Therefore, it is urgent for all workers in the field of K-12 education to form a consensus and actively improve the data literacy education and evaluation criteria system in combination with the types of new technology applications involved in the Horizon 
Report. According to the standard system, with the support and cooperation of the government, regions and schools, various forms of training and activities are actively carried out to speed up the improvement of teachers' data literacy. ${ }^{[8]}$

\subsection{Promoting the application of new technology in $\mathrm{K}-12$ education in China}

\subsubsection{Developing innovation space and promoting school space transformation}

With the rise of the Creator Movement, students' requirements for schools are not only limited to obtaining all kinds of resources they need, but also hope that schools can provide a high-quality physical space for communication, cooperation and participation in various kinds of practice. The Horizon Report provides many classic examples of makerspace, such as the Singapore Information and Communication Development Authority's "Laboratory on Wheels". Our country's K-12 education institutions can learn from the makerspace cases displayed in the Horizon Report, take the innovative activities offered by schools as the carrier, and take the resources inside and outside schools, information technology and practical tools as the support to complete the transformation of classroom, laboratory, library and other space, and develop a variety of makerspace. To create a good innovative entity environment. Adhering to the educational concept of "open innovation, inquiry experience, cooperation and sharing", we should actively carry out customer education, stimulate students' interest, realize the connection between creative inspiration and design thinking, and provide students with comprehensive learning space and opportunities for various learning exchanges and resource sharing.

\subsubsection{STEAM courses are in the ascendant, and A+ integration is strengthened}

In recent years, the development of STEM curriculum in the field of $\mathrm{K}-12$ education in China has promoted the development of learners' innovative ability. All kinds of K-12 education institutions have constructed their own characteristic STEM curriculum system to realize seamless docking between curriculum and learners, so that learners can obtain all kinds of resources and information at anytime, anywhere and according to their own preferences, and obtain people. Sexual service to maximize the individual needs of learners. In addition, with the development of the concept that art, design and humanities play an important role in the construction of comprehension and creativity, $\mathrm{A}+$ has been added to STEM to form STEAM, which requires that K-12 education institutions not only continue to teach STEM courses such as robotics, virtual reality and the Internet of Things, but also strengthen STEM. Research and exploration of integration with $\mathrm{A}+$.

\subsubsection{Promote programming as literacy and gradually develop computational thinking ability}

Professions related to program coding, especially game design, Internet development and software engineering, were rated the top three high-paying professions in China. The Horizon Report classifies the development of learners' programming literacy as a short-term trend that drives the application of new technologies in K-12 education, and the development of Computational Thinking as a "difficult challenge". It can be seen that programming and computational thinking are the skills that human beings must have in twenty-first Century. Therefore, our country's K-12 education can not only set up some coding interest courses or training camps to cultivate the interest of primary and secondary school students in this respect, but should carry out the research and exploration of programming into the regular curriculum framework, so that primary and secondary school students realize the importance of programming literacy and computational thinking, and practically train primary and secondary school students. Students' interest in programming and developing computational thinking ability will lay a solid foundation for further learning in the future.

\section{Conclusion}

The rapid development of emerging technologies has promoted the transformation and development of K-12 education. The Horizon Report focuses on the global situation, and describes the trend of new technology application in the field of K-12 education in the next five years (2017-20121), the challenges in the process of applying new technology and the new technology entering the field of K-12 education and teaching. The important development of these will have a profound impact on the development, reform and innovation of K12 education. At present, China's elementary education is also facing various new technological innovation challenges. Therefore, China's elementary education needs to proceed from the "short-term", "medium-term" and "long-term" development trends of new technologies, actively respond to challenges, prudently deal with emerging technologies, and optimize technological application programs. Scientific planning is to find an effective way to achieve a breakthrough in the transformation of China's elementary education. It is to promote the healthy and orderly development of China's elementary education from three aspects: enhancing the strategic planning and analytical ability of elementary education, improving the quality of elementary education teachers' education and their digital literacy, and promoting the application of new technologies in the field of elementary education. In addition, the Horizon Report focuses on the application of new technologies in K-12 education in Western countries, such as the United States, although it focuses on the world. In order to make up for the possible differences, the Institute of Intelligent Learning of Beijing Normal University and the New Media Consortium of the United States jointly released 
the first Chinese version of the Horizon Report "China K12 education Technology Outlook of the New Media Consortium of 2016" at the First US-China Smart Education Conference on January 14, 2016. [9] Here, I hope that we can arouse wider attention and greater interest in the educational circles, especially in the field of K-12 education, and carry out the investigation and Research on the application of educational technology in $\mathrm{K}-12$ education in China, so as to form and publish every year, which can help the leaders of primary and secondary schools and relevant decision-makers to understand in time. Report on major developments in the field of educational technology that promote teaching, learning and creative exploration.

\section{Acknowledgements}

This work was supported by the Basic Research Business Fees in Central Universities (Grants No. CF161229014295)

\section{References}

1. Freeman, A., Adams Becker, S., Cummins, M., Davis, A., and Hall Giesinger, C. (2017). NMC/Co SN Horizon Report: 2017 K-12 Edition. Austin, Texas: The New Media Consortium.

2. Yongbing $\mathrm{Hu}$, Dingwen Zhang, Ronghuai Huang. State and Trends of Global ICT in Education. China Educational Technology, 2015(1):1-5.
3. Xinfang Li, Jing Li. Application analysis and deep integration strategy of new technologies in basic education. Educational Science Research, 2017(6): 26-31+49.

4. Yibing Liu, Guangkui Fu. On the Innovation of Institution and Mechanism in the Integrative Development of Teacher Education. Educational Research, 2014(1):112.

5. Hongmei Xu, Yuanhang Song. The Theoretical Basis of Study on the Integration of Teacher Education. Journal of Social Science of Jiamusi University, 2011(4):93.

6. Zhurong Zhong. Reflection on Integration of Teacher Education and Choice of Development of Education Colleges. Teacher Education Research, 2011(11):9.

7. Lingjing Li, Cunyou Wang. Comparative Analysis of Primary and Secondary School Teachers' Skills Training in Pre-service and Post-service Education. The Chinese Journal of ICT in Education, 2017(12): 65-69.

8. Qing Li, Yizhu Ren. Review of the Current Research and Practice of Teacher's Data Literacy Education in Foreign Countries. e-Education Research, 2016(5):120-128.

9. Adams Becker, S., Huang, R., Liu, D. J., Gao, Y., Cummins, M., Hall Giesinger, C., and Shedd, L. (2017). 2017 NMC Technology Outlook for Chinese Higher Education: A Horizon Project Regional Report. 